\title{
LEONESES EN LOS CAMPOS NAZIS
}

\author{
José Luis GAVILANES LASO \\ Universidad de Salamanca
}

\begin{abstract}
RESUMEN: El presente estudio toma como asunto la nómina de deportados nacidos en León y su provincia que fallecieron o supervivieron en los campos de exterminio nazis (Mauthausen, Gusen, Dachau), explicitando caso por caso los datos conocidos sobre su biografía. Se corrigen errores e inexactitudes vigentes hasta ahora en los respectivos listados, en cuanto a las localidades de origen, fechas de nacimiento y defunción, así como otras circunstancias de tipo familiar. Se da cuenta también en este inventario de aquellos deportados fallecidos en los campos cuyas familias se beneficiaron de una indemnización por parte de las autoridades alemanas competentes al término de la segunda guerra mundial.
\end{abstract}

PALABRAS CLAVE: Deportados leoneses, campos de concentración nazis, indemnización alemana.

ABSTRACT: This study deals with the list of deportees born in Leon (Spain) and its province who died or survived in the Nazi extermination camps (Mauthausen, Gusen, Dachau), detailing case by case the facts known about their biography. Mistakes and inaccuracies left until now in the respective lists have been corrected; these relate to places of origin, dates of birth and death, as well as other family circumstances. This inventory also includes those deportees who died in the camps and whose families received compensation from the competent German authorities at the end of the Second World War.

KEYWORDS: Deportees from Leon, Nazi concentration camps, German compensation.

El listado de leoneses deportados y fallecidos en los campos de exterminio, fundamentalmente del complejo concentracionario de Mauthausen, aparece en una página web que, por provincias, ha elaborado el Centre d'Investigació Histórica de Bais Maestrat / Montsià (CEIBM). La http://w.w.w.ceibm.org/prov 26.html corresponde, pues, a la provincia de León, si bien la que ahora adjunto, aunque dimana de la del CEIBM, presenta un orden diferente, contiene nuevos datos y se subsanan algunos errores e incorrecciones. Aún así, la información disponible tras esta revisión puede ser ampliada y mejorada. Habrá que precisar, sin ir más lejos, si Carrizal es de Valderrueda o de Luna; o si Cerezal es de la Guzpeña o de Tremor, y que efectivamente se trate de aldeas leonesas y no de otras provincias. 


\begin{tabular}{|c|c|c|c|c|}
\hline Nombre & Lugar Nacimiento & Fecha Nac. & Fech Def. & Lugar \\
\hline Abella Barredo, Antonio & Paradaseca & 26-06-1912 & $05-12-41$ & Gusen \\
\hline Cano García, Segundo & Quintanilla de Rueda & 11-08-1908 & $30-12-42$ & Gusen \\
\hline Colín García, Celestino & Brugos de Fenar & 10-09-1919 & $13-01-42$ & Gusen \\
\hline Crespo López, Manuel & Lamagrande & 07-01-1906 & $29-09-41$ & Gusen \\
\hline Cuadrado Iglesias, Victoriano & S. Pedro Dueñas & $16-12-1908$ & $13-09-41$ & Gusen \\
\hline Fernández Fierro, Gabriel & Cármenes & $11-03-1914$ & $27-09-41$ & Gusen \\
\hline Fernández Seijas, Arturo & Santa Lucía & 28-04-1917 & $26-12-41$ & Gusen \\
\hline Fierro Orejas, Máximo & (Cármenes) & $18-02-1890$ & $31-01-41$ & Gusen \\
\hline Fuente Blanco, Santiago & Piedras Albas & 19-02-1908 & $09-06-41$ & Gusen \\
\hline García Alfonso, Ceferino & Tejedo de Ancares & 25-09-1907 & $10-02-42$ & Gusen \\
\hline García Gaitero, Prisciliano & Carbajal de Fuentes & 28-07-1910 & $30-06-49$ & Francia \\
\hline García Giménez, Antonio & León & 07-08-1906 & $12-11-41$ & Gusen \\
\hline González González, Elpidio & Palacios del Sil & 26-04-1900 & $24-09-41$ & Gusen \\
\hline Huerga Fierro, Ángel & Léon & 06-08-1903 & $30-05-44$ & Francia \\
\hline Morán Fernández, Marcelino & Mondreganes & 26-05-1912 & $25-06-41$ & Dachau \\
\hline Ovalle Ovalle, Agustín & San Juan de la Mata & 18-10-1901 & $12-04-42$ & Mauthausen \\
\hline Pérez Canedo, José & Balouta & 26-04-1908 & $15-01-42$ & Gusen \\
\hline Rivera Blanco, Rafael & Lomba & $11-07-1912$ & $08-12-41$ & Gusen \\
\hline Rodríguez Rguez., Valentín & Cerezal & 28-04-1913 & $28-09-41$ & Gusen \\
\hline Ruiz García, Ursicinio & Carrizal & 11-10-1921 & $21-11-41$ & Gusen \\
\hline Samprón Cereijo, Eduardo & Villasinde & 05-05-1908 & $26-10-41$ & Gusen \\
\hline Sánchez Gutiérrez, Alfredo & La Robla & 25-04-1903 & $22-04-43$ & Gusen \\
\hline Suárez González, Manuel & Canseco & 11-12-1904 & $12-10-41$ & Gusen \\
\hline Valdés Mateo, César & Cistierna & 01-04-1903 & $22-03-41$ & Gusen \\
\hline Villegas Fernández, Félix & Cármenes & 06-11-1913 & $12-08-42$ & Gusen \\
\hline
\end{tabular}

De los aproximadamente 7.000 españoles deportados a Mauthausen en distintas remesas, desde agosto de 1940 hasta el 5 de Mayo de 1945, fecha de la liberación del campo por las tropas estadounidenses, poco más de 2.000 se salvaron del régimen de esclavitud al que los nazis les sometieron o de los asesinatos puros y simples por los más variados procedimientos de exterminio imaginables que se les aplicaron. La gran mayoría de esos dos millares, o sucumbió muy pronto, o arrastró las secuelas en el cuerpo y en la mente durante toda su vida.

Es obligado decir, que la nómina de 25 fallecidos leoneses comprobados (incluyo a Prisciliano García Gaitero, pues, aunque no murió en Mauthausen ni en Gusen, allí contrajo la enfermedad que le llevaría rápidamente a la sepultura en 1949; y a Máximo Fierro Orejas, natural de Mestas-Coaña, en Asturias, pero de ascendencia y residencia en Cármenes), si bien es una cifra modesta en términos comparativos con la de otras provincias, no fue menos dolorosa que la de sus 
compatriotas de infortunio, la mayor parte de ellos catalanes, aragoneses, levantinos, andaluces y madrileños, y en menor medida de todas las demás regiones y provincias. A los integrantes de esta lista, como aconteció con el resto de los españoles, la muerte les sobrevino mayoritariamente en Gusen, sucursal del campo matriz de Mauthausen.

De todos los leoneses, sólo Agustín Ovalle Ovalle, murió en Mauthausen; Marcelino Morán Fernández hallaría su muerte en Dachau; y Manuel Crespo López, si bien figure fallecido en Gusen, en realidad, fue gaseado en el llamado "coche o camión fantasma" (una cabina blindada en la que se introducían los gases de combustión del propio vehículo), entre Mauthausen y Gusen, con el pretexto de que le iban a reparar su maltrecha salud en el "sanatorio" de Dachau. En Francia murieron, ciertamente: Ángel Huerga Fierro, cuando era trasladado a Dachau, tras el fracaso de la sublevación del penal de Eysses, donde estaba recluido; Prisciliano García Gaitero, tres años después de haber sido liberado de Dachau. Alipio Rodríguez Omaña y Rufino Baños Lozano, supervivientes de Mauthausen, moríarian también en Francia, pero bastante más tarde, a finales de los setenta y comienzos del ochenta, respectivamente

Las fechas de nacimiento oscilan —con la excepción de Máximo Fierro Orejas, bastante mayor que el resto-, desde 1900, el más viejo, a 1921, el más joven. Y las de defunción, corresponden en su mayoría a 1941.

En el sistema concentracionario de Mauthausen, además de los dos juegos de registros de prisioneros de las SS (uno destruido y otro salvado), había un tercer archivo, este secreto, hecho a mano por el español Casimiro Climent Sarrión, con la ayuda de su compatriota Juan de Diego, ambos empleados en la Politistiche Abteilung u oficina del campo. Lo que consiguieron entre los dos fue una lista de todos los prisioneros españoles, con una información suplementaria que ni siquiera los archivos de las SS contenían: la dirección en España de cada prisionero, que ellos mismos pedían a sus compañeros. Esta lista fue ocultada y, después de la liberación, sirvió de vital ayuda en la tarea de informar a las familias de aquellos que no volvieron; y también para que, en muchos casos, los familiares de las víctimas pudiesen obtener indemnizaciones de la República Federal Alemana. Con aquellos valiosos datos, Casimiro Climent y Juan de Diego confeccionaron una lista (con original y siete copias) que ocupaba 360 folios. Las copias se repartieron a la Cruz Roja Internacional, el Ministerio de Antiguos Combatientes y Víctimas de Guerra en París, la Asociación de Deportados Españoles Antifascistas (que más tarde se convertiría en la Amicale de Mauthausen), también en París, y los 
dirigentes de los cinco partidos políticos españoles o sindicatos representados en Mauthausen ${ }^{1}$ Así, comunistas, como Manuel Razola y Mariano Constante; de la CNT, como Amadeo Sinca Vendrell; o sin filiación, como Montserrat Roig y José Borrás, se sirvieron de esas listas, total o parcialmente, anexionándolas como colofón a sus respectivos libros.

De la lista del CEIBM he eliminado a Teodoro Antolín Sánchez, porque su lugar de origen no es Villasabariego, de León, sino Villasabariego de Ucieza, de la provincia de Palencia, al menos es lo que consta en la lista de la Federación de Españoles Deportados e Internados Políticos (FEDIP).

Tampoco debe figurar en la lista de leoneses que aparece en la del CEIBM, Antonio Orús Cantain, pues era aragonés, natural de Fraga (Huesca). Probablemente el hecho de que aparezca en algunas listas como de San Juan de la Mata (León), se debe a un error de correlación, al figurar junto a Agustín Ovalle Ovalle, ciertamente de la localidad berciana de San Juan de la Mata.

No todos los leoneses recluidos en Mauthausen perecieron; hubo unos pocos que consiguieron salir con vida de aquel infierno. En un listado al efecto de la FEDIP, consta Rufino Baños Lozano, nacido el 19-8-1917 en El Burgo Ranero, hijo de Lorenzo y de Vicenta. Estudió y acabó el bachillerato en el Colegio de los Maristas de León. Jugaba al fútbol en el equipo de La Estrella, de la Corredera. Probablemente la práctica de este deporte le salvó la vida cuando estuvo recluido en Gusen, del que salió liberado a primeros de mayo de 1945 . $^{2}$ Antes de llegar a Gusen, Rufino se había evadido de la zona nacional el 18 de junio de 1937, para incorporarse en Asturias al Batallón de Infantería 208, el 3 de julio de 1937. Era estudiante y estaba afiliado a la UGT con el número de carnet 91.3880. Según información recogida por la periodista Ana Gaitero, que ha establecido recientemente contacto con la esposa $\mathrm{M}^{\mathrm{a}}$ Josefa Martínez y su hijo José María,

${ }^{1}$ Cf. David Wingeate Pike (2003), p. 81.

${ }^{2}$ Aunque parezca mentira, en Mauthausen y en Gusen se jugaba al fútbol, muy probablemente para que los SS no se muriesen de aburrimiento. José de Dios Amill cuenta en su libro los pormenores de esa práctica en Mauthausen, y Marcelino López, de Toledo, declaró —en una entrevista recogida por David Wingeate Pike en el suyo - que esa actividad le salvó la vida en Gusen (p. 173). Probablemente también fue el caso de Rufino. A los presos futbolistas se les compensaba el esfuerzo con raciones de comida más abundantes. Los partidos se jugaban los domimgos en el patio de revista (Appelplatz) y eran de competición entre equipos de distintas nacionalidades. El campo era pequeño y sólo permitía jugar a ocho jugadores por equipo. El conjunto español debutó en febrero de 1941 contra Polonia y ese año ganó todos los partidos llegando a jugar la final contra Alemania, a la que ganó por un gol a cero, conquistando con ello el cinturón negro y celebrándolo con gran algazara $(C f$. DE Dios AMILL, pp. 63, 64, 72, 75, 77 y 79). 
residentes en Francia, Rufino murió en Maisons-Alfort, en 1980. Al finalizar la Guerra Civil pasó a Francia y estuvo recluido por algún tiempo en la playa de Argèles-Sur-Mer. Se alistó en el ejército francés hasta que fue hecho prisionero por los alemanes. Ingresó en Mauthausen el 27 de enero de 1941, pasando dos meses después a Gusen, con el número 43.227.

De Alipio Rodríguez Omaña sabemos que había nacido en Tapia de la Ribera el 14 de junio de 1919. En el Archivo General de la Guerra Civil, en Salamanca, consta su hoja de ingreso, libre y voluntario, en las Milicias, efectuado en Villamanín el 5 de enero de 1937, por la que se alista como antifascista en el Batallón de Asturias $\mathrm{n}^{\circ} 50$; así como su hospitalización por herida de mortero. También figura en la lista de la FEDIP, del mismo Archivo, integrado en la nómina de supervivientes de Mauthausen. Según el testimonio de su sobrina carnal, residente actualmente en León, María Ascensión Rodríguez Moreno (recogido en el artículo "Los náufragos leoneses del archipiélago de Mauthausen", firmado por Daniel Alvarez, de El Mundo. La Crónica de León), Alipio trabajó como minero en La Magdalena. Su familia le perdió la pista a la caída del frente asturiano en 1937, dándole por muerto. Posteriormente supieron por carta, que Alipio había pasado a Francia y combatía en las filas de la Resistencia. Ello le valió una condecoración, pero fue apresado por los alemanes y recluido en Mauthausen (con el número 35.080) de cuyo campo salió con vida pero con un pulmón extirpado. Alipio obtuvo la nacionalidad francesa y se casó. Vino a España varias veces a partir de la década de los sesenta y murió a finales de los años 70, tras haber montado varios negocios y volcarse en el oficio de panadero en la ciudad de Le Havre, donde actualmente vive un hijo suyo como única descendencia.

Los también leoneses: Rogelio Canedo Yebra y Felipe Morán Iglesias, de León, yVíctor Alonso Alonso, de Ponferrada, figuran en la lista de supervivientes de Mauthausen elaborado por la FEDIP, con sus respectivas fechas de nacimiento y números de deportados, de los cuales carezco, por el momento, de más información sobre biografía y paradero después de su liberación.

Pudo haber más leoneses supervivientes, además de los ya mencionados, pues en muchas de las poblaciones de origen no constan sus determinativos ni tampoco las provincias a las que pertenecen, tales como: Villafrancas, Quintanas, Chozas, Villarrodrigos, Robledos, Piedrafitas, Espinosas, Villafruelas, Oteros, Santa Lucías, etc.

Por lo tanto, el inventario de leoneses deportados en campos de exterminio nazis (supervivientes, fallecidos o desaparecidos en el tránsito hacia los mismos) 
está lejos de ser definitivo. A esta nómina, que, por lo todo lo dicho hasta aquí, sólo puede ser provisional, adhiero otras informaciones, que son las que siguen.

En primer lugar, me ocuparé de aquellos deportados leoneses caídos víctimas del régimen nacionalsocialista en Mauthausen-Gusen o en el traslado a los mismos, cuyas familias percibieron una indemnización por esta causa, aunque en modo alguno, por las razones antedichas, puede considerarse su enumeración como exhaustiva.

Al término de la segunda guerra mundial, se constituyó en París la Federación Española de Deportados e Internados Políticos (FEDIP), con sede en París, y cuyo secretario general fue el también deportado en Mauthausen, José Ester. Esta federación se creó para arrancar del Gobierno alemán el compromiso y luego el artículo correspondiente, en la ley de indemnización (BEG), a favor de las familias de los supervivientes y fallecidos residentes en España. La FEDIP puso toda la gestión en manos del secretario de pensiones, José Rodes, y del abogado francés François Herzfelder, gracias a los cuales llegó a muchas familias de deportados españoles —aquellas que pudieron aportar la documentación exigida-, sustanciosas cantidades de dinero, ${ }^{3}$ reservándose para sí el letrado francés el $12 \%$

${ }^{3}$ Para compensar a los aproximadamente veinte millones de muertos y los también aproximados tres millones de víctimas que lograron sobrevivir, el Gobierno alemán votó una suma de noventa billones de dólares. Esta cifra, a primera vista y en términos absolutos, parece impresionante, hasta el punto que se hizo popular la frase "debes más que Alemania", cuando se trataba de magnificar una deuda: Pero es relativamente minúscula comparada con la rápida prosperidad económica que alcanzó Alemania a los pocos años de haber terminado la guerra, lo que se ha traducido como el "milagro alemán". El promedio recibido por cada antiguo prisionero, una vez deducidos los gastos administrativos, fue de quinientos dólares. Si calculamos los intereses acumulados en los veinte años transcurridos desde el final de la guerra hasta el comienzo de las indemnizaciones, puede afirmarse que los alemanes, que pretendieron ser tan generosos, no han hecho más que pagar de nuevo el equivalente del coste de los vestidos, el contenido de las maletas, el anillo de bodas o el portamonedas confiscados a los presos. No pagaron nada por los automóviles, las mercancías, las factorías ni las cuentas bancarias. Ni por el trabajo realizado en los campos o por los dientes de oro extraídos de las bocas y almacenados en los bancos suizos. Alemania se convirtió pronto en la nación más próspera de Europa, tal vez — según Nerín E. Gun - porque ha dispuesto del oro, los billetes y las obras de arte robados a los internados en los campos de concentración; y porque obligaron a trabajar a millares de presos como esclavos para la Krupp, I.G.Farben, Mannesman, Messerschmidt; a excavar túneles en sus montañas; a construir fábricas en sus minas de sal, a extraer miles de toneladas de piedra de sus canteras y a destruir sus marismas. La inversión original de Alemania Occidental fue la suma total del esfuerzo y del sudor de millares de deportados, de sus pertenencias y de su muerte. La restitución se llevó a cabo con un gruñido, ya que se han tardado años de esfuerzo para obtener una compensación y se tuvo buen cuidado para impedir que la mayoría de las víctimas se enterasen de la posibilidad de tal compensación. Unos cuantos marcos al cabo de varios años de pedirlos: ¡Dios mío, qué fácil es apaciguar la conciencia! (Dachau, pp. 149 y 150) 
de lo cobrado. Toda esa documentación se encuentra depositada, desde 1991, en el Archivo General de la Guerra Civil, en Salamanca. ${ }^{4}$

A los padres de Arturo Fernández Seijas, Pedro Fernández Sacristán y Margarita Seijas García, domiciliados en la C/ General Mola, 18, de Miranda de Ebro, según consigna Isabelo Herreros - en un artículo aparecido en el Diario de León (18-7-2004) - , las autoridades francesas comunicaron oficialmente, en 1952, el fallecimiento, en Gusen, de su hijo. Expediente número 71.305. Cuando en 1968 recibieron una pensión de 220 marcos (1 marco, aproximadamente 14 pesetas de entonces), los padres de Arturo se habían desplazado a Valladolid, domiciliándose en la C/ de la Estación, no 93 - Bajo, iz., ya en edad muy avanzada. Exp. de la FEDIP, $n^{\circ} 3475$.

De Santiago Fuente Blanco, sabemos — según Isabelo Herreros- que de niño se trasladó con su familia a Buenos Aires (Argentina), de donde regresó para instalarse en Madrid. Con el tiempo llegó a ser un buen profesional en el negocio de la pescadería. Realizó el servicio militar en Pamplona, y en 1933 contrajo matrimonio con Lucía García Nicolás (los apellidos están errados en Isabelo Herreros). Alistado en el ejército republicano como voluntario, pasó a Francia en 1939. Las últimas noticias que de él llegaron a la familia datan del invierno de 1941-42, poco antes de ser capturado por la Gestapo. El Ministerio de Antiguos Combatientes y Víctimas de la Guerra de Francia comunicaron oficialmente su defunción, en 1950, a su padre, Pascual Fuente, residente en Piedras Albas. Su número de Expediente es el 71.406. En el expediente de la FEDIP n ${ }^{\circ} 3116$, la viuda del fallecido, Lucía García Nicolás, domiciliada en la C/ Mayor, 20 de Piedras Albas, recibe el 29 de marzo de 1960, 27.940 marcos y una pensión de 220 marcos

${ }^{4}$ La FEDIP fue fundada el 13 de octubre de 1945, en Tolouse, actuando como presidente honorario Francisco Largo Caballero, que también pasó cautiverio nazi en el campo de Oranienburg. En 1946 la FEDIP se trasladó a París. Su objetivo prioritario fue la salud y el bienestar de los supervivientes que estaban gravemente enfermos y no tenían familia que les ayudara. Cuando la República Federal Alemana se constituyó en Estado y lanzó el programa de ayudas (BEG), la FEDIP pidió que la cobertura alcanzase también a los supervivientes y viudas españoles. Las autoridades alemanas se la negaron con el pretexto de que, si bien los españoles fueron perseguidos, no había sido "por ser hostiles al nacionalsocialismo", sin explicar con exactitud sobre qué otra base se confinó, golpeó, torturó y asesinó a los españoles en Mauthausen y otros campos. En apelación ante el Tribunal Supremo de Colonia, el abogado francés François Herzfelder y la FEDIP consiguieron en 1954 que los supervivientes y viudas españoles recibieran una compensación de la República Federal Alemana. Curiosamente, la República Democrática Alemana no soltó ni un solo marco, por una sencilla razón: los criminales nazis provenían del oeste de Alemania y ninguno del inmaculado este. (Vid. David Wingeate Pike, (2003) pp. 476 y 477) En 1984, siendo Ministro de Cultura del Gobierno de España el ex deportado Jorge Semprún, todos los archivos de la FEDIP fueron cedidos a España a través del Consulado Español en París. 
a partir de mayo de 1960, suma de la cual se habrá de descontar el $12 \%$ de los honorarios del abogado.

Agustín Ovalle Ovalle, si bien no estaba en edad militar en 1936, se incorporó voluntario al ejército republicano en la zona leonesa hasta la caída del frente Norte en octubre de 1937. Según Isabelo Herreros, las autoridades francesas comunicaron, en 1950, el fallecimiento a la esposa, Pilar Perales Ferrer, domiciliada en la C/ Princesa, 47 de Barcelona. Tiene el expediente 72.980. Por otra parte, el número de expediente de la FEDIP es el 2387. En el mismo consta que las autoridades competentes alemanas han aceptado, en principio, la indemnización, por el período correspondiente entre el 1 de enero de 1949 y el 31 de agosto de 1960, y en virtud de ello le corresponden a la viuda un total de 28.820 marcos y una pensión, a partir del 1 de septiembre de 1960, de 220 marcos. El 19 de ese mismo mes y año recibe la beneficiaria, por conducto del Consulado Alemán de Barcelona, las indemnizaciones que le corresponden, tanto la suya como la de su hija (417.000 pesetas en total), y una pensión mensual de 3.080 pesetas.

De acuerdo con expediente de la FEDIP no 3269, Félix César Valdés Mateo dejó viuda e hijo cuando murió en Gusen en marzo de 1941. Durante su corta vida fue lo que se dice una "oveja negra", al convertirse en ferviente hombre de izquierdas en el seno de una familia hondamente enraizada en la derecha y domiciliada en Cistierna. Antes del golpe militar del 36, Valdés Mateo se encontraba en León, domiciliado en la $\mathrm{C} /$ Caño Badillo, 7, y era miembro de la Asociación de Amigos de la Unión Soviética, según consta en la investigación sobre la represión de la enseñanza en León realizada por Wenceslao Alvarez Oblanca. Durante la guerra civil, Vadés Mateo residió primeramente en Madrid, ya afiliado al Partido Comunista, desplazándose a Valencia, donde contrajo matrimonio con Dolores Muedra Culla. Pasó luego a Barcelona y posteriormente estuvo internado en un campo de refugiados en el sur de Francia, desde el que envió algunas cartas a su mujer. Con la invasión de Francia por Alemania cayó prisionero de los nazis que le internaron en Mauthausen y Gusen. La Cruz Roja Internacional comunicó a Dolores Muedra Culla la muerte de su marido. Tanto la viuda como un hijo de ambos, residentes en la $\mathrm{C} /$ Joaquín Costa, $5-8^{\circ}$, recibieron en noviembre de 1960 de las autoridades alemanas, a través del Banco de Bilbao, 364.165 pesetas con 80 centimos y 128.893 pesetas con 50 céntimos, respectivamente, en concepto de indemnización por la muerte de Valdés Mateo. Madre e hijo viven actualmente en Valencia en el citado domicilio.

Segundo Cano García era natural de Quintanilla de Rueda. Tiene el expediente de la FEDIP número 2982, y su madre Dominga Álvarez, domiciliada en Sabero, 
cobró indemnizaciones de la administración alemana, a finales de los años cincuenta. Según Isabelo Herreros, fueron las autoridades francesas competentes quienes comunicaron oficialmente, en 1950, el fallecimiento de Segundo Cano a su madre. Número de expediente del Ministerio francés 70.675.

La familia de Antonio García Jiménez tenía su domicilio cuando la guerra civil, en León, C/ Santa Ana, 17, pero se trasladó a principios de los años sesenta a la calle Tarifa número 13, donde recibió por esas fechas indemnización de la administración alemana. Los beneficiarios son la mujer del causante, Petra Ramos Ramos, y su hijo Antonio García Ramos. Expediente de la FEDIP 2974. Según Isabelo Herreros, aunque los familiares de la víctima eran vecinos de León, todo parece indicar que Antonio residía en Madrid y que se incorporó voluntario al ejército republicano. En Francia fue detenido por los alemanes y conducido a Mauthausen. Las autoridades francesas (Expediente 71.526) comunicaron oficialmente, en 1950, su defunción a la familia que, como hemos visto, en 1960 residía todavía en León.

Es difícil saber si hubo más causantes de origen leonés cuyos familiares reclamaron indemnizaciones - con resultado positivo o negativo- desde otros puntos de la geografía española en donde fijaron nueva residencia, aunque no es arriesgado aventurar que efectivamente los hubo. Sabemos que algunos leoneses de esta lista ya no estaban domiciliados, con o sin sus familiares más directos, en los lugares de nacimiento, por haber emigrado a Cataluña o a Madrid como principales puntos de destino. Existe otra dificultad añadida, puesto que en muchos de los expedientes exitosos de la FEDIP respecto a la indemnización sólo figura en la documentación el nombre de los beneficiarios, no el de la víctima que causa el beneficio. Que yo sepa hasta ahora, únicamente en estos seis casos apuntados de nativos leoneses se produjo reclamación a la República Federal Alemana con resultado positivo.

Si en el caso de otro leonés, Prisciliano García Gaitero - como veremos al final de este estudio - la reclamación, que se efectuó desde Mieres, fue infructuosa, mejor suerte tuvo un deportado extremeño víctima del holocausto nazi, anteriormente desplazado a la provincia leonesa. En este caso, las indemnizaciones por fallecimiento en campo de exterminio alemán del causante se cobraron en el pueblo leonés de Vegacervera. Se trata de Graciano Gil Iglesias, nacido en Aldea del Cano (Cáceres) el 18-12-1905 y muerto en Gusen el 7-10-1941. Estaba casado con Mariana Santos Sanguino y era padre de Crescencio y Vicente Gil Santos. Esta familia extremeña emigró y se avecindó en Vegacervera. Uno de los hijos del causante, Vicente, fue el primero en desplazarse a la localidad leonesa, trabajando primero como criado y luego en la mina, arrastrando poco después al resto de su 
familia. Mariana y Crescencio ya han fallecido y Vicente, como consecuencia del cierre de las minas en la cuenca del Torío, emigró a Puigcerdá. Al principio de la década de los sesenta, cuando comenzaron a recibir el dinero alemán, residían aún en esa localidad de la provincia de León. Expediente de la FEDIP número 3087.

Antonio Abella Barredo nació en Paradaseca, y no en León, como aparece por error en todas las listas, incluida la de la FEDIP. Según consta en una ficha con su nombre y apellidos, existente en el Archivo General de la Guerra Civil, en Salamanca, Antonio ingresó en la CNT a los 21 años y estaba enrolado en el Batallón de Infantería $n^{\circ}$ 207, conocido como "Onofre", con sede en Gijón. Su hermano menor, Silvino (más conocido por Silvano), perteneciente a la UGT, figura en el mismo archivo como natural de Paradaseca. Gracias a esa ficha he podido confirmar el lugar de origen del deportado. Silvino vive con 86 años encima, y reside en Ponferrada, en la Residencia Virgen de la Encina. En entrevista telefónica, Silvino me ha contado que durante la guerra civil, los sublevados fascistas contra la República asesinaron a su padre, y que su hermano Antonio se embarcó en Gijón ${ }^{5}$ y llegó a Cataluña. En Barcelona, según una referencia que consta en la lista de la FEDIP, mantenía un noviazgo con Filomena Baltasar, con domicilio en la C/ Sitges, $\mathrm{n}^{\circ}$ 9, a la que debieron comunicar su muerte. Pasó a Francia desde donde escribió una carta a la familia, su último testimonio vital, expresando su deseo de volver a España, pero no lo hizo al advertírsele del grave peligro que corría. Silvino, que también pasó su calvario como recluso en San Marcos, de León, y otros cautiverios en batallones de trabajo (Bilbao, Cádiz y Peñaranda de Bracamonte, cuando la reconstrucción por el estallido del polvorín, en 1939), creyó siempre que su hermano había muerto fusilado en Alemania. Casi nonagenario, Silvino se ha enterado de cómo y cuándo se produjo realmente la muerte de su hermano Antonio.

Máximo Fierro Orejas nació ocasionalmente en Mestas-Coaña (Oviedo), debido a que su padre, Paulino Fierro, natural de Cármenes, ejercía de maestro nacional en esa localidad asturiana del municipio de Cangas de Onís. Al poco de nacer, su familia regresó de nuevo a Cármenes. Máximo, más conocido popularmente por Santiago, permaneció en esa localidad leonesa hasta 1937. Estaba afiliado a la UGT y al Partido Socialista Obrero. Ejercía como alcalde y por

\footnotetext{
${ }^{5}$ A la caída del frente norte asturiano, sólo una parte de milicianos republicanos consiguió eludir a la IV Brigada de Navarra, embarcándose en Gijón con rumbo a Francia. Desde el puerto gijonés no salieron más allá de nueve o diez batallones. El resto, o cayeron prisioneros o se dispersaron por las montañas en grupos dispersos o fueron aniquilados ( $C f$. Javier RODRíGUEZ GonZÁLEZ, p.56). Quienes llegaban a Francia, ora buscaban allí acomodo, o bien se pasaban de nuevo a España por Cataluña para seguir combatiendo por la causa republicana.
} 
el Consejo de Justicia de Asturias y León fue nombrado juez municipal de Cármenes el día 2 de Enero de 1937. Al poco de este nombramiento y ante la presión de las tropas franquistas en la zona del alto Torío y la subsiguiente caída del frente asturiano, Máximo Fierro huyó a Asturias y fue de los que consiguió embarcarse en Gijón, rumbo a Francia, volviendo luego a España atravesando la frontera por Cataluña. Residió en Igualada hasta el éxodo general republicano. Su estado físico le obligaba ya, desde hacía tiempo, a caminar con muletas, cuando llegó al campo de concentración de Argelés-Sur-Mer, en el sur de Francia. Fue detenido más tarde por los alemanes y transportado a Mauthausen con la primera expedición de españoles, en agosto de 1940, ya cumplidos los cincuenta años de edad. También integró el primer grupo de españoles desplazados de Mauthausen que llegó a Gusen el 24 de enero de 1941. A los que estaban demasiado débiles o enfermos para trabajar en Mauthausen les decían que eran enviados a Gusen "para cuidar de su salud". Si el primer español sucumbió en Gusen dos días después de la llegada, el final de Máximo Fierro coincidió con el último día de enero de 1941, probablemente a causa de una ducha fría, el método de liquidación por excelencia en ese campo. En conversación que he mantenido con su sobrino carnal, el escritor Ángel Fierro, su tío Máximo era una persona muy cultivada tanto cuentas como artes. En el Archivo de la Guerra Civil, en Salamanca, existen varias fichas a su nombre y una hoja de su historial político y profesional, extendido el 7 de enero de 1947 por la Sección Político-Social encabezada por José Gómez Hernández. Fierro Orejas fue de esas víctimas ilustradas, de talante liberal, cuyo "pecado imperdonable" consistió en intentar la concordia de los dos bandos confrontados, oponiéndose tanto a los desmanes de los "rojos" como de los "blancos". Pero, obligado a entrar en la refriega de las dos actitudes irreconciliables, se vio encerrado en un callejón sin salida, pues la izquierda más extrema desconfiaba de él como individuo sospechoso y la derecha trasmontana lo consideraba como radical enemigo de su causa.

José Pérez Canedo figura en la lista que cierra el libro de Razola y Constante ${ }^{6}$, de segundo apellido como Cando, aunque sí es correcto el nombre y apellidos en la de Sinca Vendrell, ${ }^{7}$ y también en la de la FEDIP. Sin embargo, no es correcto que sea natural de Malanta y Malonta, como se consigna respectivamente en ambos libros y en el listado de la FEDIP, pues son localidades inexistentes; siendo, en realidad — según mi propia pesquisa—, natural de Balouta, e hijo de José Pérez Suárez.

\footnotetext{
${ }^{6}$ Vid. Manuel Razola y Mariano COnSTANTE, (1979), p. 284.

${ }^{7}$ Que aparece en su libro Lo que Dante no pudo imaginar, p. 204.
} 
Sobre Ceferino García Alfonso existía la duda de si era natural de Tejedo del Sil o de Tejedo de Ancares, pues el lugar de origen en la lista de la CEIBM aparecía restringido a Tejedo. He conseguido averiguar que el lugar de origen es Tejedo de Ancares. La familia emigró a Cataluña, pero regresó a Tejedo, desplazándose con posterioridad a El Barco de Valdeorras, donde reside actualmente.

De Elpidio González González, de momento sólo sé que viajó entre los deportados que embarcaron en la estación de ferrocarril de Angouleme, en el famoso por infame convoy que les llevó a Mauthausen. Su hermana, Araceli González González, vivía en C/ Ayuntamiento nº 1, de Palacios del Sil.

A la muerte de Rafael Rivera Blanco, aún vivía su madre, Petra Blanco, domiciliada en $\mathrm{C} / \mathrm{La}$ Canalexa, $\mathrm{n}^{\circ} 5$, de la localidad natal de Lomba.

De Marcelino Morán Fernández sabemos que era hijo de Pedro, el herrero de Mondreganes, y de Isidra, en esta aldea de la Tierra de Campos perteneciente al Ayuntamiento de Cebanico. Prestó servicio militar en el Regimiento de Caballería de la $8^{\text {a }}$ zona, de guarnición en León. Emigró a Barcelona, en 1934, donde ingresó en el cuerpo de guardias de asalto, alcanzando el grado de cabo en 1936. En noviembre de 1938 pasó al 32 Grupo de Asalto de la Compañía de Seguridad (SIM). Figura con interrogantes respecto a sus fechas de nacimiento y defunción en las listas del CEIBM de deportados de la provincia de León, pero su nombre y apellidos, con la fecha y lugar de nacimiento correctos, constan en el archivo de Dachau. Fue trasladado de Mauthausen a Dachau, el día 1 de mayo de 1941, y registrado con el número 25.538, muriendo en Dachau el 25 de junio de 1941. Cuándo, por qué y dónde fue arrestado no está registrado en Dachau ni en ningún otro de los archivos consultados, exceptuando el de Arolsen. Curiosamente, en el Archivo General de la Guerra Civil, en Salamanaca, existe, además de su ficha, otra con el mismo nombre y apellidos, que corresponde a un soriano, hijo de Ciriaco y de Gertrudis, ingresado en el mismo grupo de asalto, en febrero de 1937. La Cruz Roja Internacional comunicó a la familia el fallecimiento de Marcelino en un "hospital" de Alemania. Con posterioridad, su familia se desplazó de Mondreganes a la localidad de Almanza (León). Actualmente viven dos medios hermanos: Eugenia Morán, en Baracaldo; y Emiliano Morán, en León.

El leonés Manuel Crespo López llevaba la matrícula de prisionero 13.011, integrando una lista de deportados que iban destinados desde Gusen al "sanatorio" de Dachau, pero, en realidad, fue gaseado en el "camión fantasma", el 14 de agosto 
de 1941, pues ninguno de los inscritos en esa lista jamás llegaron a Dachau. ${ }^{8}$ Según Isabelo Herreros, en 1950, las autoridades francesas comunicaron oficialmente su fallecimiento a un amigo suyo llamado Enrique Herrera, con domicilio en $\mathrm{C} /$ Bellafila, 5 de Barcelona. Número de Expediente 70.992.

El segundo apellido de Eduardo Samprón, no es Cercijo - como se consigna en la lista alfabética de deportados leoneses del CEIBM-, ni tampoco Creuze como también, erróneamente, consta en la ficha existente en el Archivo General de la Guerra Civil, en Salamanca-; pues su segundo apellido verdadero es Cereijo. Antes de la guerra, toda su familia vendió la propiedad y emigró a Cataluña. En Barcelona, Eduardo ingresó en el Cuerpo de Seguridad Interior de la Generalidad de Cataluña. Existe un documento en el Archivo General de la Guerra Civil, en Salamanca, fechado en Barcelona el 2 de abril de 1938, de su puño y letra, dirigido al Consejero de Gobierno de la Generalidad, en el que se constata que Eduardo había ingresado en el citado cuerpo en 1934, y por haber permanecido en él cuatro años sin ninguna tacha grave en su expediente, solicita acogerse a los beneficios según la Orden de 28 de agosto de 1920, que le da derecho a un premio a la constancia. La solicitud está avalada por la firma del teniente coronel Eduardo Cuevas de la Peña. Según Isabelo Herreros, las autoridades francesas comunicaron oficialmente, en 1950, la defunción a su padre, Antonio Samprón Martín, por entonces domiciliado en la C/ San Fernando, 125, de Camagüey (Cuba). Expediente número 73.714 .

De Alfredo Sánchez Gutiérrez, sostiene Isabelo Herreros, que las autoridades francesas comunicaron oficialmente la defunción, en 1950, a su madre, Mercedes Gutiérrez Rodríguez, domiciliada en la $\mathrm{C} /$ Cotenillo, de La Robla. Número de Expediente 73.745

A los familiares de Manuel Suárez González, residentes en Canseco, según Isabelo Herreros, las autoridades competentes francesas comunicaron oficialmente, en 1950, el fallecimiento a su hermano Zacarías, domiciliado en la C/ Palombera, de Canseco, en 1950. En este caso el Sr. Herreros no indica número de expediente. Otras dos hermanas del deportado habían emigrado a América.

Celestino Colín García, pertenecía a una familia muy conocida en el valle de Fenar. Su padre era el herrero de Brugos de Fenar, y Celestino le ayudaba en la fragua. Parece que se alistó voluntario en julio de 1936 en el bando republicano. En junio de 1950, sostiene el Sr. Herreros, que las autoridades francesas comunicaron

\footnotetext{
${ }^{8}$ Entre los que, como se puede comprobar, aparece en un listado que ilustra el libro de Mariano Constante Yo fui ordenanza de los SS, p. 84.
} 
oficialmente su fallecimiento a la madre, Genoveva García, residente en Brugos de Fenar. Número de expediente 70.907.

En 1950, según el Sr. Herreros, las autoridades francesas comunicaron oficialmente a su tío, Felipe Cuadrado, domiciliado en San Pedro de las Dueñas, Ayuntamiento de Sahagún, el fallecimiento de Victoriano Cuadrado Iglesias. Expediente número 71.007.

Gabriel Fernández Fierro, nació en la pedanía de Almuzara, perteneciente al municipio de Cármenes. En 1936 se encontraba integrado en las unidades que sostuvieron en la montaña leonesa la legalidad republicana, hasta la caída del frente asturiano en 1937. Como tantos otros pasó a Francia en 1939. Según el Sr. Herreros, en 1952, las autoridades francesas comunicaron oficialmente el fallecimiento a su madre, Catalina Fierro Orejas, vecina de Cármenes. Expediente número 71.258 .

De Félix Villegas Fernández sabemos, además de sus lugares y fechas de nacimiento y defunción, que al término de la guerra civil, su madre, Tomasa Fernández, estaba domiciliada en la calle Cáceres, número 5, de Madrid.

Me inclino a creer que Ursicinio Ruiz García nació en Carrizal de Luna, y no en Carrizal-Valderrueda. En el Archivo General de la Guerra Civil, en Salamanca, figura la hoja con su firma de alistamiento en las milicias del ejército republicano, efectuado en Villamanín el 15 de enero de 1937.Tuvo peor suerte en Gusen que sus paisanos Rufino Baños Lozano y Alipio Rodríguez Omaña, que consiguieron salir vivosy con los cuales hay indicios de que mantuvo una cierta amistad.

Otro republicano leonés - no incluido en la lista del CEIBM, ni en la de la FEDIP, ni en la de Isabelo Herreros-, cuya muerte aconteció cuando iba a ser trasladado al campo de Dachau, era Ángel Huerga Fierro. Si bien no puedo aseverarlo, por el momento, su lugar de nacimiento tuvo lugar probablemente en la capital de la provincia. Sí, en cambio, sabemos con certeza tanto la fecha de nacimiento, como el lugar, la fecha y circunstancias de su defunción. Nació el 6 de agosto de 1903 y murió camino de la estación ferroviaria francesa de Penne d'Angenais, el 30 de mayo de 1944. En 1936 residía en Madrid como estudiante, domiciliado en la calle P. Olavide, 12, soltero y enrolado en el Partido Comunista el 30 de agosto de ese mismo año. Existe su ficha, acompañada de fotografía tamaño carnet, en el Archivo General de la Guerra Civil, en Salamanca. ${ }^{9}$ Sobre su muerte tenemos varios testimonios. Eduardo Pons Prades lo menciona en uno de

\footnotetext{
${ }^{9}$ Serie militar, caja 665 .
} 
sus libros, ${ }^{10}$ y Antonio Soriano hace lo propio en el suyo. ${ }^{11}$ Pero el testimonio más directo nos lo ha dado recientemente el francés André Lecuyer, en un escrito publicado en Rouen el 3 de septiembre de 2001. Ángel Huerga Fierro estaba internado en la prisión de Eysses (matriculado con el número 374), en el distrito de Lot-et-Garonne, cárcel donde los franceses encerraban a los presos considerados más peligrosos. En ese penal estaban recluidos como prisioneros políticos un total de 1.200 franceses y 170 españoles cuando, el 19 de febrero de 1944, se produjo una sublevación con la colaboración del "maquis" exterior. Pero la rebelión fue sofocada, hubo un juicio sumarísimo y los alemanes fusilaron a doce presos, entre ellos a dos españoles. El resto de presos fue deportado a Alemania, al campo de Dachau. El día del traslado, 30 de mayo de 1944, la mayor parte de los detenidos fueron transportados en camiones hacia la estación, pero otros, unos ochenta, entre los que está Ángel Huerga, hubieron de hacerlo a pie, por la carretera de Eysses hasta la estación de Penne d'Angenais. Según André Lecuyer, Ángel caminaba en el medio del convoy, mientras Lecuyer iba en la parte final de la columna de presos, lo que le permitió ver a cómo tres o cuatro SS sacaban al español fuera del grupo y se ensañaban con él brutalmente a patadas y culatazos. El motivo, al parecer y siguiendo con el testimonio de André, fue un cinto que Ángel llevaba, con la hoz y el martillo grabados, que había conseguido pasar clandestinamente burlando la vigilancia de sus guardianes. André juzga del todo imposible que Ángel consiguiese salir con vida después de recibir aquella terrible paliza. Otra versión del hecho añade que los alemanes, tras haberse cebado con aquel cuerpo sin defensa, dieron fin a su suplicio disparándole un tiro en la nuca. Este leonés descansa para siempre en el cementerio de Compiègne, tumba 4471, sección 23, bajo una lápida que tiene la inscripción "Mort pour la France", honor póstumo que le fue concedido por decisión de las autoridades francesas el 27 de diciembre de $1948 .^{12}$

De todos los leoneses que pasaron por los campos de exterminio nazis, Prisciliano García Gaitero fue el que llegó a conocer mayor número de ellos y el único que dejó testimonio por escrito de su pavoroso paso por los mismos.

Nacido en Carvajal de Fuentes, al quedar huérfano de padre, Serafín García Gozález, Prisciliano emigró a Mieres con su madre, Valentina Gaitero de la Iglesia, natural de Valdemora, quien contrajo nuevo matrimonio. Cursó en esa localidad

${ }^{10}$ Vid. Republicanos españoles en la segunda guerra mundial, p.179 y p.182

11 Vid. Éxodos. Historia oral del exilio republicano en Francia 1939-1945, p. 129, en la entrevista que hace a Juan Martorell, superviviente de Dachau.

${ }^{12}$ Vid. página Web: $<$ http//bteysses.fre.fr/Temoignages/Huerga.html $>$ 
minera asturiana estudios primarios en el colegio de los Hermanos de la Salle. Muy joven entra a trabajar como rampero en el interior del Grupo Minero Mariana, de la Fábrica de Mieres. En 1931 causa baja por tener que cumplir el servicio militar como enfermero en Larache. Vuelve de nuevo a la mina asturiana en Diciembre de 1932, con un sueldo de 500 pesetas, lo que le permite vivir con cierto desahogo. Con la crisis del 34 trabaja en régimen de "terceras", esto es, un día de cada tres. Por esas fechas se alista en el Partido Comunista. Cuando estalla la guerra civil, causa de nuevo baja en la mina, en la que había ascendido a la categoría de picador, y se alista en el ejército republicano, combatiendo en el frente norte. A la caída de éste, en 1937, Prisciliano se refugia en el monte, pero aprovechando la confusión reinante, baja a los pocos días a Oviedo y se enrola como voluntario en La Candellada. De haber regresado a Mieres hubiera sido fatal para él, pues ya andaban en su búsqueda para fusilarlo. Es conducido a Huesca, enrolado en un batallón de trabajo que realiza labores de fortificación en Abena, cerca de Jaca, en la provincia de Huesca, desde donde envía varias cartas a su familia. Pero al tener noticias de que están detrás de él en Asturias, incluso encarcelado a su madre para que se entregue, Prisciliano decide escapar a Cataluña. En Barcelona, según dos documentos existentes en el Archivo de la Guerra Civil, en Salamanca, recibe una recompensa por evasión de la zona facciosa y se da una orden para darle alojamiento por tratarse de un "buen camarada". En 1938, ya irremediable la derrota republicana, consigue pasar a Francia en compañía de su inseparable amigo, el impresor de Tortosa, José Brull Solares. En Francia trabaja como jornalero en distintas granjas desde donde envía, en el transcurso de 1940, varias cartas y postales a la familia. En una de ellas les anuncia su deseo de viajar a Méjico, pero el intento acaba frustrado. Cuando las tropas de Hitler invaden Francia, Prisciliano es apresado por los alemanes el 21 de junio de 1940, en Voves, cerca de Chartres, a unos cien kilómetros de París.

Los esfuerzos de su familia para conseguir su repatriación fracasaron. El primer teniente de alcalde en funciones de Mieres, Luis Rubiera Zubizarreta, certificaba el 8 de agosto de 1940 que: "Prisciliano García Gaitero, de filiación comunista, miembro del Socorro Rojo Internacional es, a pesar de su ideología, persona de buena conducta". La respuesta de las autoridades españolas competentes para negarse a la solicitud de repatriación se basó —en un alarde de cínica perversiónen que, como en el expediente de Prisciliano no constaba que hubiese cometido delitos de sangre ni de otro tipo, no se justificaba su repatriación.

Prisciliano viaja en tren varios días hacinado en un vagón de ganado hasta el campo de prisioneros de guerra Stalag $X-B$, en Sandbostel, entre Bremen y Hamburgo, desde donde establece un último contacto epistolar con la familia, que no se restablecerá hasta tres años más tarde. En este campo permanece hasta el 
traslado, esta vez viajando en tren regular, a Mauthausen, adonde llega el 28 de febrero de 1941. Mauthausen sólo será para Prisciliano lugar de paso, pues al cabo de un mes consigue ir voluntario a Gusen, para acompañar a su amigo José Brull, que ha sufrido una herida y está inútil para trabajar. Allí verá morir a su amigo y a otros muchos compatriotas. Cuando, al cabo de unos meses, lo más lógico era que hubiera ido al crematorio - dado su precario estado de salud, debido sobre todo a haber contraído una tuberculosis ósea - a Prisciliano, conjuntamente con varias centenas de prisioneros, se le transporta a Dachau, el 8 de noviembre de 1942, sin que hasta ahora se sepa la razón verdadera de ese traslado. Desde este campo envía varias cartas a la familia, cumpliendo la norma estricta de las 25 líneas sólo para expresar que está "en el mejor de los mundos posibles". La familia se dirige el 13 de junio de 1944 al Consulado General de España en Francia, con sede en París, para conseguir la repatriación de Prisciliano, con la única respuesta: "Se han emprendido las gestiones oportunas". Será gracias a la ayuda solidaria, tanto en Gusen como en Dachau, ${ }^{13}$ de sus compatriotas y de los ex brigadistas internacionales, también internos, por lo que Prisciliano conseguirá sobrevivir hasta el 29 de abril de 1945, cuando los americanos liberan el campo.

Prisciliano es trasladado a Francia, donde también recibe generosa ayuda, especialmente de los Srs. Materraz, un matrimonio francés que le acogió como a un hijo y le dispensó todos los cuidados posibles, y de Mildred Fahrni, su otra

${ }^{13}$ Vid. el testimonio de Patricio Serrano, Santiago Raga y Ricardo Rico sobre el campo de Gusen en el libro de Manuel Razola y Mariano Constante, (1979): "En estos convoyes partieron excelentes camaradas, como García Prisciliano (sic), de Mieres (Asturias). A menudo estuvo entre la vida y la muerte como consecuencia de los golpes recibidos en la cantera y logró salir sano y salvo gracias a la ayuda de José [Sanz] y de Ricardo [Raga]. Una noche, al encontrarse muy mal, hizo venir a Patricio a su lado y le dio a conocer algunos hechos de su pasado y sus ideas sobre el futuro. Patricio comunicó más adelante esos datos a José y Ricardo, caso de que él también llegase a morir. Pero, por increíble que esto parezca, García sobrevivió, fue trasladado a otro campo, se benefició de la ayuda de presos políticos alemanes y, después de la Liberación, se le encontró en París en un hospital, aquejado de una gangrena de la que fallecería poco tiempo después." (p. 184).

Ricardo Rico, en el testimonio que ofreció a Javier Alfaya, consigna la siguiente dedicatoria: "Este relato está dedicado a los camaradas Prisciliano García, Simón Perales, José Castillo y Félix Aznares, queriendo personificar en ellos a los miles de compatriotas y amigos caídos en estos siniestros lugares." Vid. Javier AlfayA, (1970) p. 25.

Y el brigadista austriaco Hans LANDAUER (2004): "En Dachau yo estuve hasta el final de la guerra. Y siempre estaba acompañado de españoles, uno de ellos de León, Prisciliano García. Recuerdo que el 8 de noviembre de 1942 llegó un transporte con inválidos trasladados a Dachau. sólo eran piel y huesos, pesaban 35 ó 40 kilos. Y los brigadistas, que éramos unos 400 en el campo y teníamos influencia, los protegimos, aunque murieron muchos de ellos (...) Fue un gran amigo, tanto, que a mi hijo lo bauticé como Prisciliano en su honor. Era de León, pero recuerdo que cantaba mucho aquello de Asturias patria querida..." (p.33). 
"madrina de guerra" canadiense. Trabaja en una mercería y en la confección de pantalones, hasta que el agravamiento de la enfermedad que padecía hizo necesaria su hospitalización en el sanatorio de Brevannes, donde falleció el 30 de junio de 1949, a los 39 años.

Los periódicos franceses que publicaron la noticia de su muerte destacaban "su férrea voluntad para no volver a ver aquello que sus ojos contemplaron". Un antiguo compañero de cautiverio dirigió unas palabras en el entierro de este asturleonés que "toda su vida había luchado por un ideal: la defensa de las libertades republicanas, tanto en España como en Francia". Sus restos yacen en el cementerio de Fontenay-sous-Bois bajo una lápida con la inscripción "Mort pour la France".

La familia de Prisciliano realizó, a finales de la década de los cincuenta y principios y mediados de los sesenta, y a través de la FEDIP, bajo la dirección del secretario de pensiones José Rodes y del abogado Fraçois Herzfelder, infructuosas gestiones para que Valentina Gaitero de la Iglesia, en precaria situación económica, pudiera acogerse a la indemnización que la República Federal Alemana había establecido para recompensar a las familias de los supervivientes y víctimas de la persecución nacionalsocialista. Pero, como su hijo Prisciliano no murió dentro de los campos, ni inmediatamente después, sino al cabo de cuatro años; ni tampoco los informes médicos fueron lo suficientemente concluyentes para demostrar que las causas del fallecimiento estaban relacionadas con los padecimientos sufridos en Mauthausen, Gusen y Dachau, le fue denegada cualquier indemnización por parte de la administración alemana.

Prisciliano nos dejó unas memorias de su paso por los tres campos de exterminio nazis, con el único propósito de denunciar lo que allí vivió. Estas memorias las recogió su madre cuando se trasladó a Francia al saber que el hijo se le moría. No llegó a verlo vivo, pero trajo con ella a España, como si un pedazo aún de vida de su hijo se tratase, oculto entre el vestido y los pechos que un día lo amamantaron, un cuaderno de notas que Prisciliano fue escribiendo mientras luchaba por agarrarse inútilmente a la vida. De ese cuaderno, la familia de Prisciliano hizo 15 ejemplares en edición facsímil, que distribuyó, además de un ejemplar para la Biblioteca Nacional, entre distintas instituciones asturianas ${ }^{14}$.

${ }^{14}$ Vid. Gavilanes Laso, J. L., Mi vida en los campos de muerte nazis. Memorias de Prisciliano García Gaitero, Edilesa, León, 2005 


\section{BIBLIOGRAFÍA SUMARIA}

ALFAYA, Javier (1976). «Españoles en los campos de concentración nazis» en El exilio español de 1939, José Luis Abellán (org.), vol. II. Madrid: Ed. Turner.

AlfAYA, Javier (1970). «Españoles bajo el III Reich», en Los Suplementos. Madrid: Ed. Cuadernos para el Diálogo,pp. 5-43.

AlvarEZ, Daniel (2005) «Los náufragos leoneses del archipiélago de Mauthausen»: El Mundo. La Crónica de León, León: 5 de mayo, p. 14.

BERMEJO, Benito (2002). Francisco Boix, el fotógrafo de Mauthausen: Barcelona, RBA Ediciones.

CONSTANTE, Mariano (1984). Los años rojos. Zaragoza: Nogara-Libros.

Constante, Mariano (1976). Yo fui ordenanza de los SS..Barcelona: Ed. Martínez Roca.

GAITERO, Ana (2005). «Rotspanier 43.227»: en El Diario de León, León: 9 de mayo, pp, 27 y 28.

GAVILANES LASO, José Luis (2004) «Leoneses en los campos de la muerte», en Diario de León. Rev. Filandón, no 923, León: 12 de septiembre, pp. 1-5.

Gavilanes LASO, José Luis (2005). «Leoneses en Dachau»: en Diario de León. Rev. Filandón, no 953, León: 17 de abril, pp. 1, 4 y 5.

E. GuN, Nerín (1972). Dachau. Barcelona: Ed. Bruguera.

HERrERos, Isabelo (2004). «Leoneses desaparecidos en Mauthausen», en Diario de León. Revista, León: 18 de julio, pp. 5-7.

LANDAUER, Hans (2004) entrevista en Diario de León, León: 15 de noviembre,

MASSAGUER BRUC, Lope (1977). Mauthausen, fin de trayecto Madrid: Fundación de Estudios Libertarios Anselmo Lorenzo.

PONS PRADES, Eduardo (1970). «Republicanos españoles en los campos nazís», en Historia y Vida, no 30, Madrid: septiembre, pp. 22-35.

PONS PRADES, Eduardo (1995).Morir por la libertad,Madrid: Ed. Vosa.

PONS PRADES, Eduardo (2003). Republicanos españoles en la segunda guerra mundial, Madrid: La Esfera de los Libros.

PONS PRADES E. y CONSTANTE, M. (1978). Los cerdos del comandante. Barcelona: Argos/Vergara.

Razola, M. y Constante, M. (1979). Triángulo azul. Los republicanos españoles en Mauthausen. Barcelona: Ed. Península.

RoDRÍGUEZ GONZÁLEZ, J, (2003). León bajo la dictadura franquista (1936-1951). León, Universidad de León.

RoIG, Montserrat (1978). Noche y Niebla. Los catalanes en los campos nazis. Barcelona: Ed. Península.

SincA Vendrell, Amadeo (1980). Lo que Dante no pudo imaginar. Barcelona: Producciones Editoriales. 
SORIANO, Antonio (1989). Éxodos. Historia oral del exilio republicano en Francia. Barcelona: Ed. Crítica.

VILANOVA, Antonio (1969). Los olvidados. Los exiliados españoles en la segunda guerra mundial. París: Ed. Ruedo Ibérico.

Wingeate PiKe, David (2003). Españoles en el holocausto. Barcelona: Ed. Mondadori. 


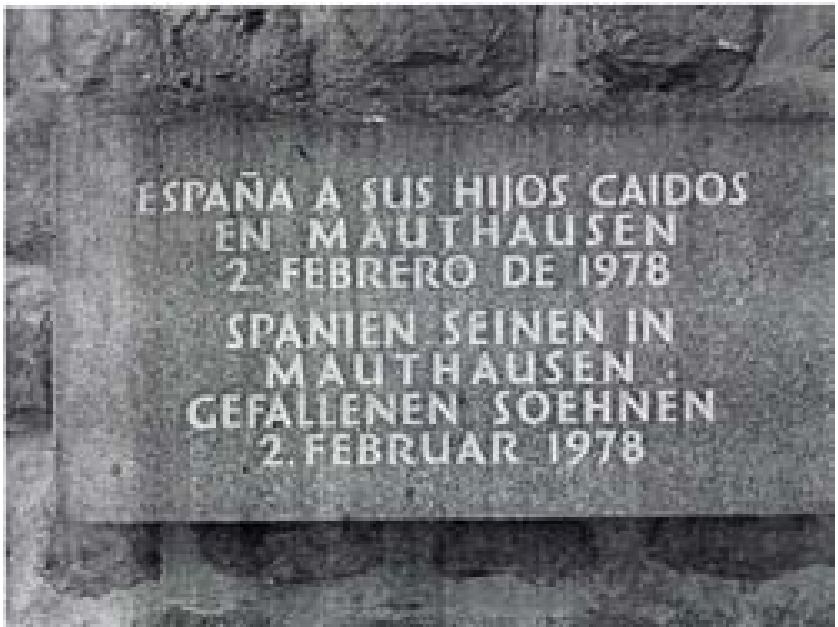

Figura 1

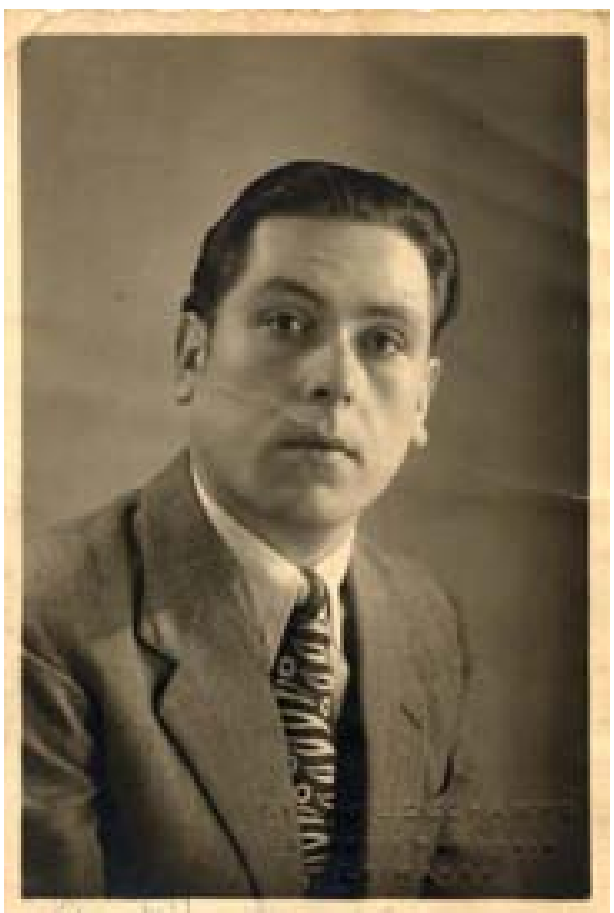

Figura 2: Alipio Rodríguez Omaña 
José Luis Gavilanes Laso

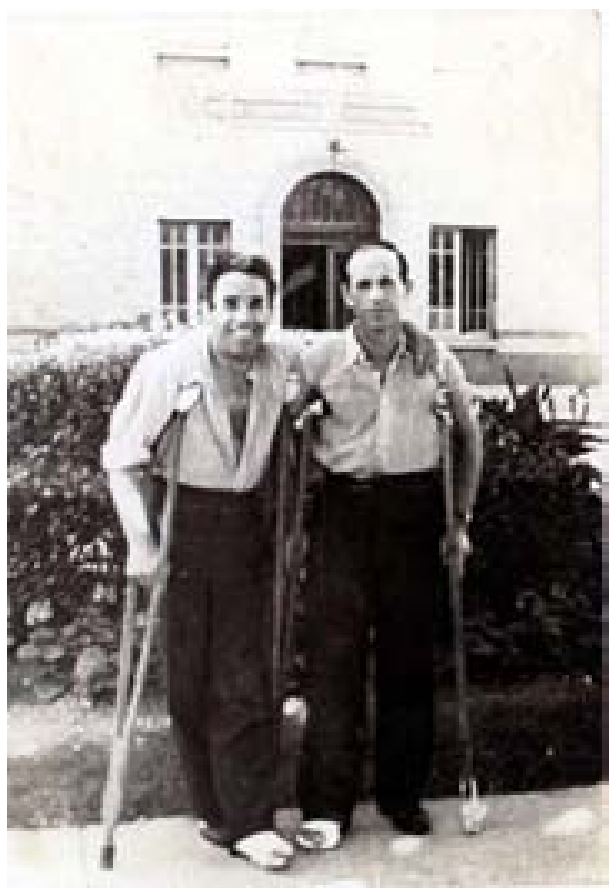

Figura 3: Prisciliano García Gaitero (izda.)

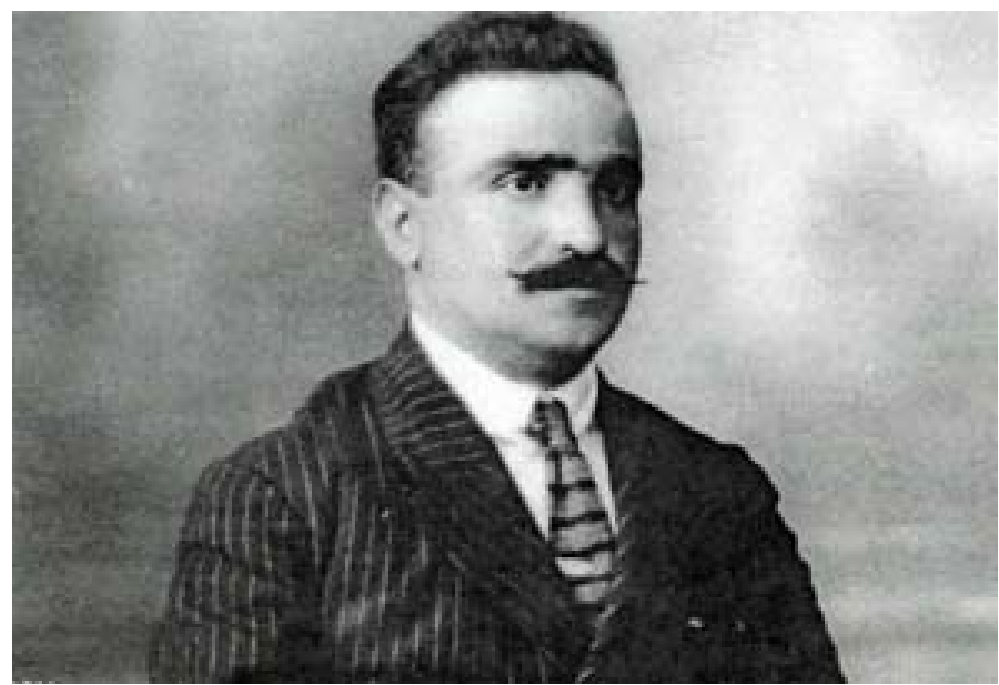

Figura 4: Máximo Fierro Orejas 


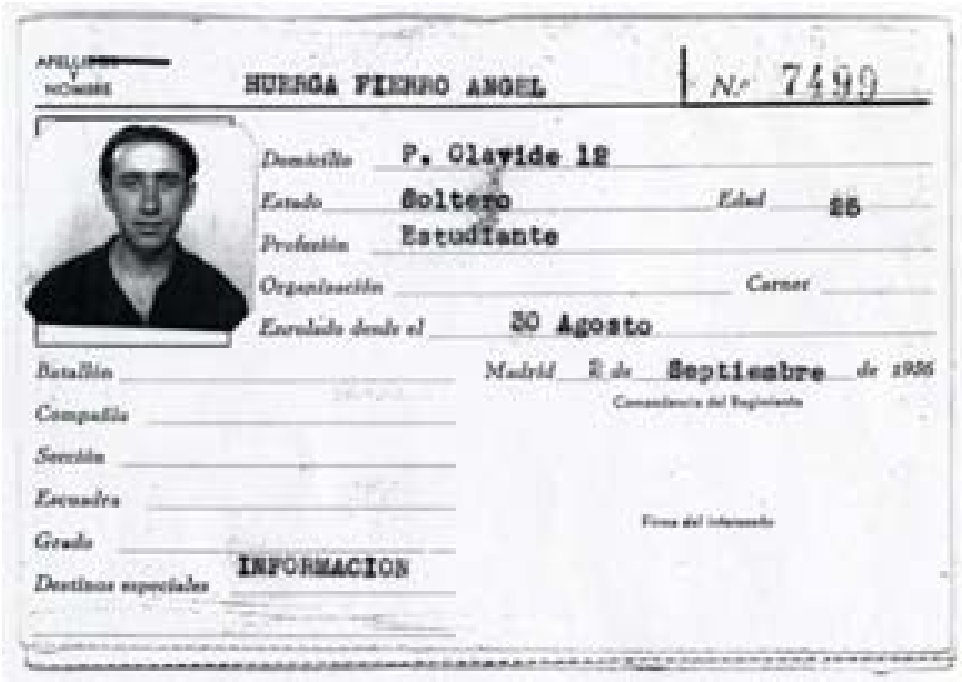

Figura 5: Ángel Huerga Fierro

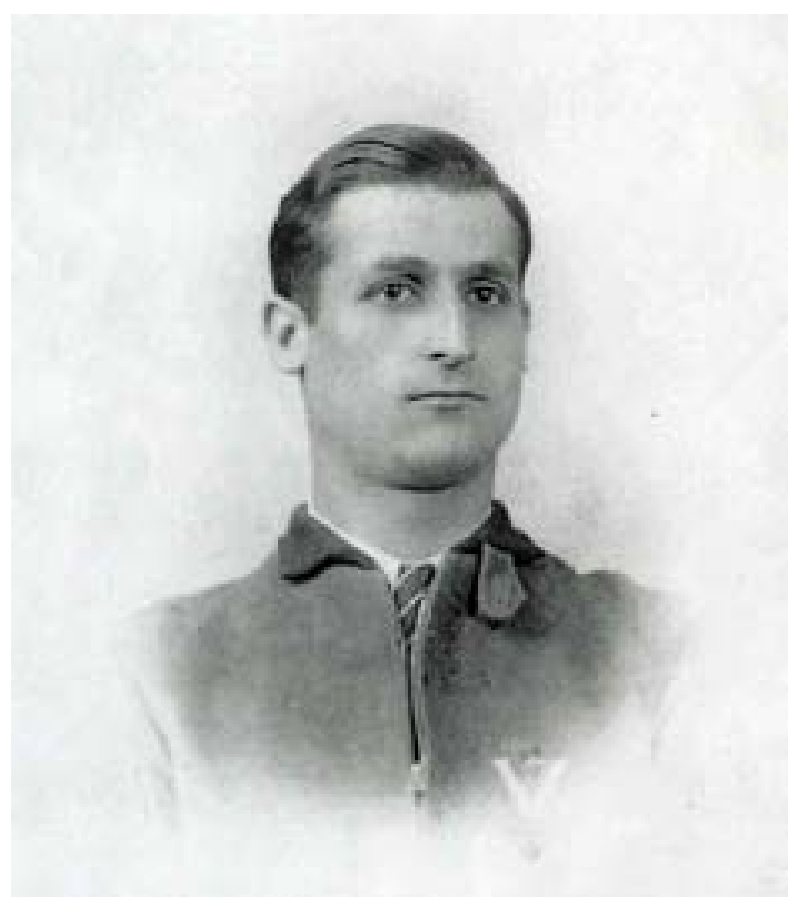

Figura 6: Marcelino Morán Fernández 
